\title{
Penile Length and Anogenital Distance in Male Newborns From Different Iranian Ethnicities in Golestan Province
}

\author{
Ehsan Alaee ${ }^{1}$; Mohammad Javad Gharib ${ }^{2}$; Mahnaz Fouladinejad ${ }^{1,}$ \\ ${ }^{1}$ Neonatal and Children's Health Research Center, Golestan University of Medical Sciences, Gorgan, IR Iran \\ ${ }^{2}$ Department of Pediatrics, Tehran University of Medical Sciences, Tehran, IR Iran \\ ${ }^{*}$ Corresponding Author: Mahnaz Fouladinejad, Neonatal and Children's Health Research Center, Golestan University of Medical Sciences, Gorgan, IR Iran. Tel: +98-1715547680, E-mail: \\ m_fouladinejad@yahoo.com
}

Received: December 9, 2013; Revised: August 3, 2014; Accepted: August 27, 2014

Background: Anogenital distance (AGD) is a feasible and accepted parameter of exogenous or endogenous androgens effects on development of reproductive system.

Objectives: Since there is no report on penile length (PL) and AGD in our region, we investigated these parameters in male newborns in Golestan Province, Iran.

Patients and Methods: In this cross-sectional study, we measured stretched PLand AGD in term newborns from different races in Dezyani Gynecologic Hospital of Gorgan, Iran. We also recorded the anthropometric parameters and maternal age. The data was analyzed using the SPSS 14.

Results: Means of PL and AGD of 427 healthy term newborns were $32.1 \pm 3.5$ and $24.5 \pm 2.5 \mathrm{~mm}$, respectively. There was a positive correlation between PL and AGD $(r=0.097, P=0.046)$. According to their ethnicity, there were 166 Fars (38.9\%), 129 Turkmen (30.2\%), and 132 Sistani (30.9\%) infants with mean PL of respectively $31.8 \pm 3.9,32.3 \pm 3.3$, and $32.4 \pm 3.3 \mathrm{~mm}$ and mean AGD of respectively $25 \pm 2.5,24.3 \pm 2.5$, and $24 \pm$ $2.5 \mathrm{~mm}$. One Fars neonate $(0.23 \%)$ had micropenis $(\mathrm{PL}=21.3 \mathrm{~mm})$.

Conclusions:Using -2.5 standard deviations as the cutoff for micropenis, a newborn infant in Golestan Province with a PL of $<23.3 \mathrm{~mm}$ had micropenis; however, more investigations are needed to clarify this issue.

Keywords:Ethnic Groups; Anthropometry; Male; Iran

\section{Background}

Examination of the genitalia is part of the physical examination of all neonates. Size abnormalities of the external genitalia in male and female newborns might be the first sign of underlying endocrine or genetic disorders such as congenital hypopituitarism (1). Micropenis is a condition, in which a penis is abnormally small while perfectly formed without hypospadias or epispadias and is usually defined as a penis that has a stretched length of shorter than 2.5 standard deviations (SD) below the mean (2). Isolated micropenis is an inadequate virilization disorder that results from a hormone defect arising after week 14 of embryonic development (3). It might be presented in Noonan and Robinow syndromes as well as in chromosomal abnormalities such as Klinefelter's and Prader-Willi syndromes (4). Nowadays, anogenital distance (AGD) is used for investigations on fetal androgen activity and reproductive toxicities in experimental animals and humans (5-8). Several studies have shown that males have a greater AGD than females, in both animals and humans (9-11). Comorbidity of shorter AGD with hypospadias and cryptorchidism was seen in human males (9). Recently, Mendiola et al. reported a strong correlation of AGD with all semen parameters and its predictive value for low sperm concentration in adult males (8). Therefore, early measurement of penile length (PL) and AGD can help us find underlying masculinization defects and predict future reproductive health of newborns. PL is reported to vary between different races and ethnicities in several studies $(1,12-16)$. Reference values based on local normative data for PL are important for the early diagnosis and treatment of potential diseases. To our knowledge, there are no published studies from our region establishing normal values for PL and AGD of newborn males.

\section{Objectives}

This study aimed to demonstrate and compare the norms of PL and AGD in term newborn infants in Golestan Province, northern Iran, and assess inter-racial differences in our population. We also evaluated the association between PL and anthropometric measures such as body weight and length.

\section{Patients and Methods}

This cross-sectional study was conducted in Dezyani Hospital of Gorgan, Golestan Province, northern Iran. A total of 427 full-term (37-42 weeks) healthy male infants,

Copyright (C) 2014, Iranian Red Crescent Medical Journal. This is an open-access article distributed under the terms of the Creative Commons Attribution-NonCommercial 4.0 International License (http://creativecommons.org/licenses/by-nc/4.0/) which permits copy and redistribute the material just in noncommercial usages, provided the original work is properly cited. 
who were born between March 2011 and March 2012, were included. While there is a rich cultural and racial variety in the Golestan Province, we measured PL and AGD in newborns from three main ethnicities including Fars, Turkmen, and Sistani to compare the results among them. Written informed consent was obtained from parents before all evaluations. The Ethics Committee of Golestan University of Medical Sciences approved this study (code, 6309102319). Neonates with ambiguous genitalia, hypospadias, undescended testis, multiple maternal anomalies, endocrine disorders, admission in NICU, and neonates of mothers who took androgens during pregnancy were excluded. Three patients were excluded from the study because of some congenital urological malformations, two with undescended testes and one with hypospadias. Gestational age was calculated according to the last menstrual period or the age based on sonography before the week 20 . In case of uncertain gestational age, the Ballard score examination was performed within the first 24 hours of life to determine the gestational age. Sampling was done by screening method; we included every single healthy male newborn who was born in our hospital. The stretched PL and AGD were measured in supine position. For measuring PL, the penis was gently stretched to the point of maximum resistance and a ruler (VYCON) was pressed alongside the penis onto the pubic bone. The PL was measured at the level of the top of the glans penis excluding the foreskin $(10,11)$. For measurement of AGD, both hip and knee joints were in flexion and gentle pressure was applied on both legs towards the abdomen and the distance between the center of anus and posterior base of scrotum was recorded (10, 11). All measurements were performed by a single examiner whose proficiency was validated before the study. Measurements were repeated three times for each newborn in the first day of life and the mean was recorded as the final value.

The results were expressed as means and standard de- viations (SD). Micropenis was calculated and defined as $\mathrm{PL}<$ [mean PL - $(2.5 \times \mathrm{SD})]$ in each ethnic group and total study population. According to Ting et al. (15) and results of a pilot study with sample size of $18,=0.05,=0.1$, maximum error of 0.9 sample size for each ethnic group (Fars, Turkmen), $\mu_{1}=32, \mu_{2}=33.6$, and $\delta_{1}=4.4, \delta_{2}=3.4$, the sample size in each ethnic group was calculated at 129. The expected power of study was $90 \%$. Normal distribution of data was evaluated by Shapiro-Wilk's test. The oneway ANOVA was used for comparisons and the Pearson's correlation test was applied to assess the associations among parameters. The data was analyzed using the SPSS 14 (SPSS Inc, Chicago, IL, USA). P < 0.05 was regarded as statistically significant.

\section{Results}

A total of 427 term male newborns were included in the study. Mean and SD of weight, height and head circumference in the first day of birth were $3.3 \pm 0.4 \mathrm{~kg}, 49.2 \pm 2.1$ $\mathrm{cm}$, and $35 \pm 1.2 \mathrm{~cm}$, respectively. Mean maternal age was $26.9 \pm 5.5$ years. Mean PL and AGD in study subjects were $32.1 \pm 3.5 \mathrm{~mm}$ and $24.4 \pm 2.5 \mathrm{~mm}$, respectively (Figure 1 ). There was a statistically significant positive correlation between PL and AGD $(r=0.097, \mathrm{P}=0.046)$ and there was a significant negative correlation between PL and infants' head circumference $(\mathrm{r}=-0.098, \mathrm{P}=0.043)$. According to their ethnicity, there were 166 Fars (38.9\%), 129 Turkmen (30.2\%), and 132 Sistani (30.9\%). Mean \pm SD and range of PL and AGD in different ethnic groups are shown in Table 1. There was no significant difference in PL among ethnic groups but AGD in Fars neonates was the highest and statistically different from Turkmen $(\mathrm{P}=0.04)$ and Sistani $(\mathrm{P}=0.003)$ neonates. As previously described, micropenis definition was calculated for each ethnicity and total study population as shown in Table 1 . In our study, one Fars neonate $(0.23 \%)$ was had micropenis $(\mathrm{PL}=21.3 \mathrm{~mm})$ that diagnostic and therapeutic approach was started for him.
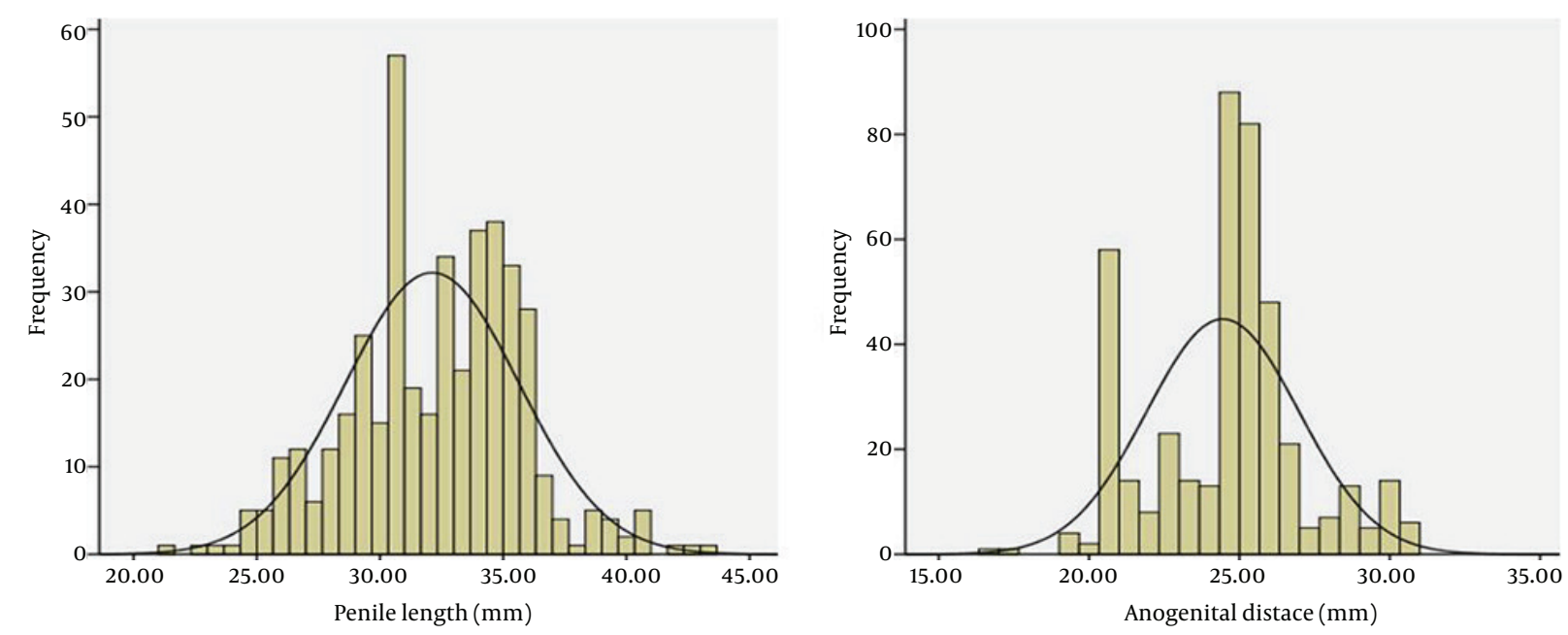

Figure 1. Distribution of Penile Length and Anogenital Distance of Iranian Newborn Infants From Golestan Province, Iran 
Alaee E et al.

\begin{tabular}{|c|c|c|c|c|}
\hline Parameter & Fars $(n=166)$ & $\operatorname{Turkmen}(\mathbf{n}=\mathbf{1 2 9})$ & Sistani $(\mathbf{n}=132)$ & Total $(n=427)$ \\
\hline Penile Length, mm & $31.8 \pm 3.9[21.3-41.3]$ & $32.3 \pm 3.3[24.7-40.7]$ & $32.4 \pm 3.3[24.3-40.7]$ & $32.1 \pm 3.5[21.3-43.3]$ \\
\hline PValue & $\begin{array}{l}\text { Compared to Turkmen } \\
\qquad(\mathrm{P}=0.543)\end{array}$ & $\begin{array}{l}\text { Compared to Sistani } \\
\qquad(\mathrm{P}=0.981)\end{array}$ & $\begin{array}{l}\text { Compared to Fars } \\
\qquad(\mathrm{P}=0.418)\end{array}$ & $\mathrm{P}=0.388$ \\
\hline Anogenital Distance, mm & $25 \pm 2.5[17.3-30.3]$ & $24.3 \pm 2.5[20.7-29.7]$ & $24 \pm 2.5[16.7-29.7]$ & $24.5 \pm 2.5[16.7-30.3]$ \\
\hline P Value & $\begin{array}{l}\text { Compared to Turkmen } \\
\qquad(\mathrm{P}=0.04)\end{array}$ & $\begin{array}{l}\text { Compared to Sistani } \\
\qquad(\mathrm{P}=0.673)\end{array}$ & $\begin{array}{l}\text { Compared to Fars } \\
\qquad(P=0.03)\end{array}$ & $P=0.002$ \\
\hline Micropenis Definition, $\mathbf{m m}^{\mathrm{a}}$ & $\mathrm{PL}<22.2$ & $\mathrm{PL}<24.1$ & $\mathrm{PL}<24.1$ & $\mathrm{PL}<23.3$ \\
\hline
\end{tabular}

${ }^{\mathrm{a}}$ Data are presented as mean $\pm \mathrm{SD}$ [range]

$\mathrm{b}$ Micropenis is defined as follows: mean PL $-(2.5 \times \mathrm{SD})$.

\section{Discussion}

In comparison with other parts of the world, the mean PL of term newborns form Golestan Province seemed to be more similar to European newborns. Specifically, Kutlu et al. (4) and Thankamony et al. (10) reported a mean PL of $31.5 \pm 5$ and $30 \pm 4$ form Turkey and England, respectively. Moreover, Ting et al. reported PL of $35 \pm 4 \mathrm{~mm}$ in Malaysia (15), Al-Herbish reported $36.5 \pm 5 \mathrm{~mm}$ in 379 Saudi Arabian infants (17), Feldman and Smith reported a mean PL of $35 \pm 7 \mathrm{~mm}$ in 37 Caucasian term newborn infants in the United States (18), and Vasudevan et al. from India reported PL of $36 \pm 5 \mathrm{~mm}$ in 135 South Indian infants (19). Our measurements of AGD were similar to the reports from the United States and Nigeria $(23 \pm 3.8$ and $25.8 \pm 1.1 \mathrm{~mm}$, respectively) $(20,21)$. Salazar-Martinez et al. reported mean AGD of $21 \pm 3 \mathrm{~mm}$ from Mexico (11) and Thankamony et al. reported AGD of $19.8 \pm 6.1 \mathrm{~mm}$ (10), both different from our results. According to the results of our study, the ethnicity had no significant effect on PL but would affect AGD. Ting et al. (15) also reported no difference between PL of Chinese, Malay, and Indian infants ( $\mathrm{PL}=35 \pm 4 \mathrm{~mm}$ ) but other studies by Lian et al. (12) reported of $35 \pm 3 \mathrm{~mm}$ for Chinese, $36 \pm 4 \mathrm{~mm}$ for Malay, and $38 \pm 4 \mathrm{~mm}$ for Indian infants and Cheng et al. (14) showed significant difference between races. Regarding the significant difference of AGD between races, our findings were similar to report of Sathyanarayana et al. (20) who reported longer AGD in Caucasian male infants in comparison to compared to Asian or native American $(\mathrm{P}=$ 0.033 ). In this study, $\mathrm{PL}<23.3 \mathrm{~mm}$ in an Iranian newborn was determined as micropenis and necessitated further laboratory and clinical evaluations. Specifically in Fars, Turkmen, and Sistani neonates in whom the micropenis was defined as $\mathrm{PL}<22.2,<24.1$, and $<24.1 \mathrm{~mm}$, respectively. In other reports from Singapore, Malaysia, Turkey, and England, the micropenis was defined as $\mathrm{PL}<26,<25$, $<21.9$, and $<20 \mathrm{~mm}$, respectively $(10,12,15,22)$. Numerous studies have demonstrate validity of AGD as a sensitive marker for the effects of intrauterine exposure to androgens and chemicals with anti-androgen effects (2325). Consequently, AGD has been identified as one of the endpoints in the United States Environmental Protection
Agency guidelines for reproductive toxicity studies in humans (26). Therefore, its changes in comparison to normal population might predict future sexual and fertility disorders (10). According to the results of our study, there is a positive correlation between PL and AGD. Romano-Riquer et al. reported a positive correlation between PL and $\operatorname{AGD}(\mathrm{r}=0.03, \mathrm{P}=0.046)$ in a group of 781 Mexican infants (27). Thankamony et al. also reported positive correlation between PL and AGD ( $\mathrm{r}=0.18, \mathrm{P}=0.003)(10)$. Observed differences in reported PL and AGD might be due to interracial differences between different study populations. Thankamony et al. suggested systematic error measurements as a reason of differences between reported values (10). Considering the results of present study along with similar reports, the correlation between PL and AGD might suggest using AGD as a measure of genital development in males, as previously was shown for PL.

\section{Acknowledgements}

Hereby, we appreciate Deputy for Research and Technology of Golestan University of Medical Sciences for technical and financial support.

\section{Authors' Contributions}

Ehsan Alaee and Mahnaz Fouladinejad designed and coordinated the study, participated in most of the experiments, and prepared the manuscript. Mohammad Javad Gharib coordinated and performed all the experiments and participated in manuscript preparation. All authors have read and approved the content of the manuscript.

\section{Funding/Support}

This study was funded by Research and Technology Department of Golestan University of Medical Sciences.

\section{References}

1. Phillip M, De Boer C, Pilpel D, Karplus M, Sofer S. Clitoral and penile sizes of full term newborns in two different ethnic groups. $J$ Pediatr Endocrinol Metab.1996;9(2):175-9.

2. Aaronson IA. Micropenis: medical and surgical implications. $J$ Urol.1994;152(1):4-14

3. Wang $\mathrm{CH}$, Lin WD, Bau DT, Tsai CH, Liu DC, Tsai FJ. Penile length 
of normal boys in Taiwan. Acta Paediatr Taiwan. 2006;47(6):293-6.

4. Kutlu AO. Normative data for penile length in Turkish newborns. J Clin Res Pediatr Endocrinol. 2010;2(3):107-10.

5. Bowman CJ, Barlow NJ, Turner KJ, Wallace DG, Foster PM. Effects of in utero exposure to finasteride on androgen-dependent reproductive development in the male rat. Toxicol Sci. 2003;74(2):393406.

6. Eisenberg ML, Hsieh MH, Walters RC, Krasnow R, Lipshultz LI. The relationship between anogenital distance, fatherhood, and fertility in adult men. PLoS One. 2011;6(5).

7. Fok TF, Hon KL, So HK, Wong E, Ng PC, Chang A, et al. Normative data of penile length for term Chinese newborns. Biol Neonate. 2005;87(4):242-5.

8. Mendiola J, Stahlhut RW, Jorgensen N, Liu F, Swan SH. Shorter anogenital distance predicts poorer semen quality in young men in Rochester, New York. Environ Health Perspect. 2011;119(7):958-63.

9. Hsieh MH, Breyer BN, Eisenberg ML, Baskin LS. Associations among hypospadias, cryptorchidism, anogenital distance, and endocrine disruption. Curr Urol Rep. 2008;9(2):137-42.

10. Thankamony A, Ong KK, Dunger DB, Acerini CL, Hughes IA. Anogenital distance from birth to 2 years: a population study. Environ Health Perspect. 2009;117(11):1786-90.

11. Salazar-Martinez E, Romano-Riquer P, Yanez-Marquez E, Longnecker MP, Hernandez-Avila M. Anogenital distance in human male and female newborns: a descriptive, cross-sectional study. Environ Health. 2004;3(1):8.

12. Lian WB, Lee WR, Ho LY. Penile length of newborns in Singapore. J Pediatr Endocrinol Metab. 2000;13(1):55-62.

13. Flatau E, Josefsberg Z, Reisner SH, Bialik O, Laron Z. Penile size in the newborn infant. J Pediatr.1975;87(4):663-4.

14. Cheng PK, Chanoine JP. Should the definition of micropenis vary according to ethnicity? Horm Res. 2001;55(6):278-81.

15. Ting TH, Wu LL. Penile length of term newborn infants in multiracial Malaysia. Singapore Med J. 2009;50(8):817-21.

16. Boas M, Boisen KA, Virtanen HE, Kaleva M, Suomi AM, Schmidt IM et al. Postnatal penile length and growth rate correlate to serum testosterone levels: a longitudinal study of 1962 normal boys. Eur JEndocrinol. 2006;154(1):125-9.

17. Al-Herbish AS. Standard penile size for normal full term newborns in the Saudi population. Saudi Med J. 2002;23(3):314-6.

18. Feldman KW, Smith DW. Fetal phallic growth and penile standards for newborn male infants. J Pediatr. 1975;86(3):395-8.

19. Vasudevan G, Manivarmane , Bhat BV, Bhatia BD, Kumar S. Genital standards for south Indian male newborns. Indian J Pediatr. 1995;62(5):593-6.

20. Sathyanarayana S, Beard L, Zhou C, Grady R. Measurement and correlates of ano-genital distance in healthy, newborn infants. Int J Androl. 2010;33(2):317-23.

21. Orish CN, Didia BC. Anogenital distance in human male and female newborns: A look at a cross section of a Nigerian population. Internet J Biol Anthropol . 2009;3(2).

22. Akin Y, Ercan O, Telatar B, Tarhan F. Penile size in term newborn infants. Turk J Pediatr. 2011;53(3):301-7.

23. McIntyre BS, Barlow NJ, Foster PM. Androgen-mediated development in male rat offspring exposed to flutamide in utero: permanence and correlation of early postnatal changes in anogenital distance and nipple retention with malformations in androgendependent tissues. Toxicol Sci. 2001;62(2):236-49.

24. Mylchreest E, Wallace DG, Cattley RC, Foster PM. Dose-dependent alterations in androgen-regulated male reproductive development in rats exposed to $\mathrm{Di}(\mathrm{n}$-butyl) phthalate during late gestation. Toxicol Sci. 2000;55(1):143-51.

25. Wolf CJ, LeBlanc GA, Gray LE, Jr. Interactive effects of vinclozolin and testosterone propionate on pregnancy and sexual differentiation of the male and female SD rat. Toxicol Sci. 2004;78(1):135-43.

26. Acerini CL, Hughes IA. Endocrine disrupting chemicals: a new and emerging public health problem? Arch Dis Child. 2006;91(8):633-41.

27. Romano-Riquer SP, Hernandez-Avila M, Gladen BC, Cupul-Uicab LA, Longnecker MP. Reliability and determinants of anogenital distance and penis dimensions in male newborns from Chiapas, Mexico. Paediatr Perinat Epidemiol. 2007;21(3):219-28. 